BMJ

Open

Gastroenterology

\title{
A male Korean who was diagnosed with chronic enteropathy associated with SLCO2A1 (CEAS): case report with literature review
}

\author{
Xi Sun, ${ }^{1,2}$ Naoki Hosoe, ${ }^{1}$ Ryoichi Miyanaga ${ }^{3}$ Kayoko Kimura, ${ }^{1}$ Shinta Mizuno, ${ }^{3}$ \\ Kaoru Takabayashi, ${ }^{1}$ Makoto Naganuma, ${ }^{3}$ Hironori Niizeki, ${ }^{4}$ Atsuhito Seki, ${ }^{5}$ \\ Haruhiko Ogata, ${ }^{1}$ Takanori Kanai ${ }^{3}$
}

\begin{abstract}
To cite: Sun X, Hosoe N, Miyanaga $\mathrm{R}$, et al. A male Korean who was diagnosed with chronic enteropathy associated with SLCO2A1 (CEAS): case report with literature review. BMJ Open Gastro 2018;5:e000223. doi:10.1136/ bmjgast-2018-000223
\end{abstract}

- Additional material is published online only. To view please visit the journal online (http://dx.doi.org/10.1136/ bmjgast-2018-000223).

Received 29 June 2018 Revised 21 September 2018 Accepted 24 September 2018

Check for updates

(c) Author(s) (or their employer(s)) 2018. Re-use permitted under CC BY-NC. No commercial re-use. See rights and permissions. Published by BMJ.

For numbered affiliations see end of article.

Correspondence to Dr Naoki Hosoe; nhosoe@keio.jp

\begin{abstract}
Objective To further disseminate the nomenclature of chronic enteropathy associated with SLCO2A1 (CEAS), especially for physicians in China and Korea where the genetic feature of $S L C O 2 A 1$ gene mutations related hypertrophic osteoarthropathy and pachydermia had been extensively studied. SLCO2A1 gene mutations related hypertrophic osteoarthropathy and pachydermia had been extensively studied.
\end{abstract}

Design A case report with literature review of SLCO2A1 gene mutations-related disorders.

Results A 38-year-old Korean presented to a tertiary hospital with dizziness, abdominal pain and melena. He had a positive faecal occult blood test on initial workup. Oesophagogastroduodenal endoscopy (OGD), colonoscopy and CT scan were unremarkable and showed no obvious cause for his melena. Capsule endoscope and roentgen barium studies were performed, revealing an erythematous mucosa with ulcers in the jejunum and stenosis to the jejunal-ileal junction. Next-generation sequencing was then performed and discovered point mutations of SLCO2A1 gene's seven exon $(940+1 \mathrm{G}>\mathrm{A})$ and 13 exon (1807 C>T) allele. This Korean patient with CEAS is the first documented case noted outside of the Japanese population.

Conclusion CEAS is not uniquely found in Japanese individuals. There are lots of similarities between CEAS and primary hypertrophic osteoarthropathy, the two entity may just be the two sides of one same coin. International and multidisciplined efforts are required to further study this complicated disorder.

\section{INTRODUCTION}

The diagnosis of multiple small intestinal ulcers with strictures is challenging as this morphological change could be associated with Crohn's disease, non-steroidal anti-inflammatory drugs, tuberculosis, Behcet's disease and other unknown aetiologies. ${ }^{1}$ The increased use of balloon-assisted enteroscopy (BAE) and capsule endoscopy in recent years allows us to examine an extensive area of the small intestine. As a result, the understanding towards small intestinal disorders have been much improved. ${ }^{1}$ In 2006, a Japanese group lead by Matsumoto has proposed chronic non-specific multiple ulcers of the small intestine (CNSU), a novel nomenclature which is distinct from disorders mentioned previously. ${ }^{2}{ }^{3}$ CNSU is an autosomal recessive inherited disorder; clinically, it is characterised by abdominal pain, chronic anaemia and hypoproteinaemia. ${ }^{2}{ }^{3}$ Approximately, 200 patients have been diagnosed with CNSU in Japan since its introduction. By means of next-generation sequencing (NGS), this Japanese team has further identified SLCO2A1 gene mutations in a certain group of patients with CNSU. ${ }^{3}$ This phenotype of CNSU was later defined as "chronic enteropathy associated with SLCO2Al' (CEAS) which is a more accurate term compared with $\mathrm{CNSU}{ }^{4}$ Besides small intestinal lesions, CEAS is also associated with multiple-organ involvements such as hypertrophic osteoarthropathy and pachydermia. ${ }^{35}$

To date, no patients of non-Japanese ethnicity have ever been diagnosed with CEAS. We present a case report in which a Korean patient has recently been confirmed to be affected with CEAS.

\section{CASE REPORT}

A 38-year-old man of Korean descend and now living in Japan presented to the outpatient clinic of a local hospital with abdominal pain, melena and dizziness. Laboratory test showed that he had microcytic anaemia (haemoglobin $8.7 \mathrm{~g} / \mathrm{dL}$ and mean corpuscular volume 71.7 fL). Faecal occult blood test was positive. His medical history included a previous duodenal bulb perforation which required surgery in his teens. Oesophagogastroduodenal endoscopy (OGD) and colonoscopy was subsequently performed, revealing no active bleeding but 


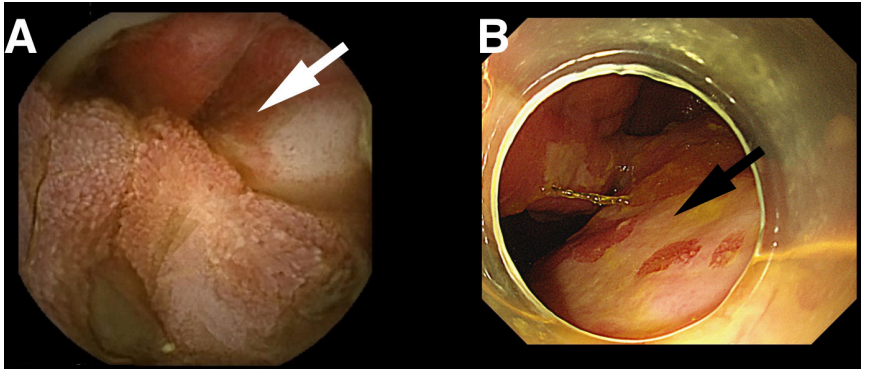

Figure 1 (A) Small intestinal ulcer surrounding erythematous mucosal changes were revealed in small intestine by capsule endoscope (white arrow). (B) Balloonassisted enteroscopy (with hood attached) revealed geographic ulcer in the jejunal-ileac junction (black arrow).

slightly deformity and linear scares in duodenal bulb. A plain CT scan later performed revealing no abdominal or pelvic masses. The patient received transfusion of two units of red blood cells which restored his haemoglobin to $11.5 \mathrm{~g} /$ $\mathrm{dL}$, relieving his symptoms significantly. He was discharged on day 12 and later referred to our hospital, a metropolitan centre in central Tokyo, for further workup and treatment.

In the diagnostic workup, chronic iron deficiency anaemia caused by small intestinal bleeding was considered. BAE (single balloon, rectal approach) was hence performed in search of the culprit lesion. However, the scope failed to advance to the jejunum; mild inflammatory changes were found in the proximal ileum. Capsule endoscopy was further performed to inspect the small intestine. There was initially a delayed pylorus passing of the capsule endoscope due to stenosis in the duodenal bulb, but the capsule eventually reached to the small intestine. Images from the capsule showed small intestinal ulceration with surrounding erythematous mucosal changes in jejunum, which were likely to be the cause of the recent bleed (figure 1A). Several days later, a plain abdominal X-ray was performed confirming capsule retention in distal small intestine. As a result, a secondary BAE (single balloon, rectal approach) was performed to retrieve the capsule. Despite the stenosis in area surrounding the jejunum-ileac junction, the scope was successfully inserted to the proximal ileum revealing geographic ulcers in the jejunal-ileac junction (figure 1B). The retrieval of the capsule was successfully done. A Roentgen barium study was later performed, which revealed small intestinal morphological changes that were similar to the earlier endoscopic findings, such as mild stenosis with deformity of duodenal bulb (figure 2) as well as stenosis in jejunal-ileac junction along with proximal dilatation (figure 2).

Based on the clinical findings above, we were suspicious that this patient was likely to be affected with CEAS. In order for this condition to be diagnosed, his blood was obtained for genetic testing. NGS was performed in the laboratory, revealing point mutations of SLCO2A1 gene's 7 exon $(940+1 \mathrm{G}>\mathrm{A})$ and 13 exon $(1807 \mathrm{C}>\mathrm{T})$ allele using the MiSeq method (Illumina corp). Additionally, a brain MRI showed mild pachydermia in the forehead which was later confirmed by a dermatologist (online supplementary figure 1). There

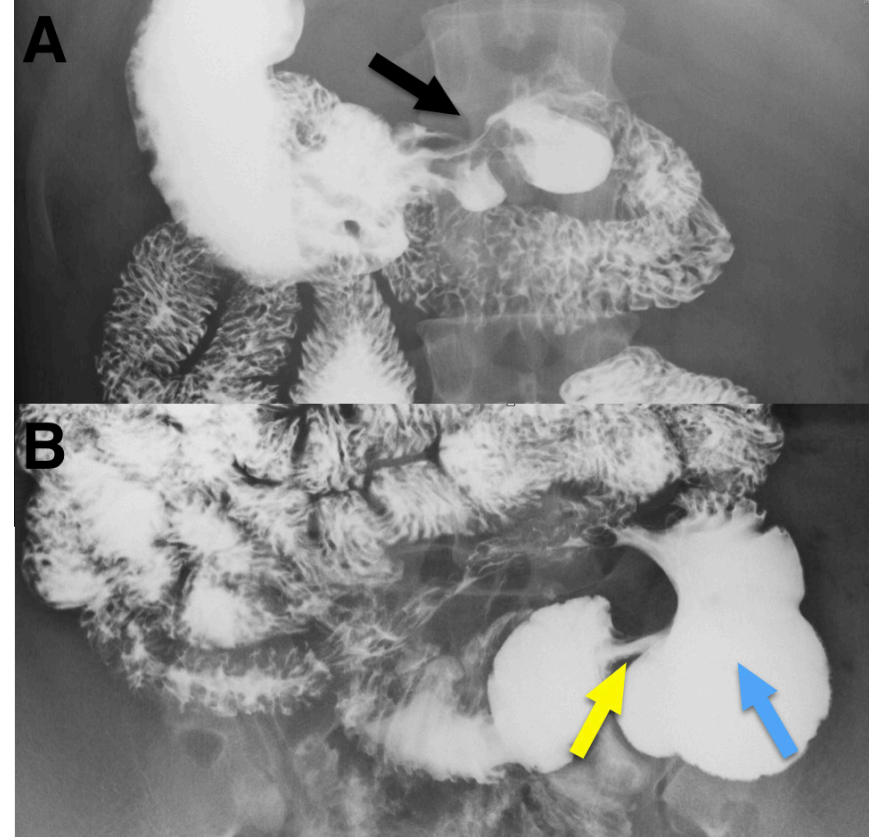

Figure 2 (A) Mild deformity in the duodenal bulb (black arrow). (B) Stenosis in jejunal-ileac junction (yellow arrow) with proximal dilatation (blue arrow).

was minimal change on fingers, toes and long bones, but it is unlikely to be typical finding of clubbed fingers or other changes on hypertrophic osteoarthropathy, however.

Based on the results of the NGS, morphological changes to the small intestine and clinical presentation, a diagnosis of CEAS was made. Since his presentation, the patient's general condition has since improved, but still intermittently complaints about abdominal pain and diarrhoea.

\section{DISCUSSION}

Multiple small intestinal ulcers of unknown aetiologies was defined as cryptogenic multifocal ulcerous stenosing enteritis (CMUSE) in Europe as early as in 1960s. ${ }^{6}$ This term has been widely used in Korea and China even to this day. ${ }^{7-9}$ In Japan, however, Matsumoto et al proposed CNSU, which is a distinct condition from CMUSE based on endoscopic, pathological features and clinical manifestations. ${ }^{2}$

The application of NGS has further improved our understanding of CNSU. Umeno et al discovered SLCO2A1 gene mutations in a certain group of patients with CNSU. This group of patients commonly have associated features such as clubbed finger, pachydermia or hypertrophic osteoarthropathy. This led to the proposal of a new entity called CEAS. ${ }^{4}$ In a recent study, Hosoe et al gathered information from 20 clinically confirmed CEAS cases. ${ }^{45}$ Based on these findings, the clinical and endoscopic features of this rare disease have been extensively studied. Currently, as CEAS is only known to a select few Japanese gastroenterologists, this novel condition has not been widely recognised yet. To our knowledge, this case is the first clinically confirmed case of CEAS in the non-Japanese ethnic group, which leads us to believe that CEAS may not be specific to the Japanese ethnicity but can affect people of other ethnicity as well. Moreover, we believe 
that there might have been cases of CEAS misdiagnosed as CMUSE or other disorders, especially in Asian countries like Korea and China. ${ }^{8}$

Differentiating between CEAS and CMUSE can be difficult without a gene test as patients with either conditions can present clinically with anaemia and abdominal pain. Furthermore, both CEAS and CMUSE are characterised by multiple small intestinal ulcers on gross endoscopic examination. Although we have previously demonstrated that the ulcers of CEAS and CMUSE present with different distributions and shapes, this conclusion was based on comparison between small sampled studies. ${ }^{5} 8$ Zhang et al had discovered PLA2G4A gene mutations in a pair of Chinese siblings who were both diagnosed with CMUSE. ${ }^{9}$ Unfortunately, no patients with CMUSE from Korea and European countries have received a test for $S L C O 2 A 1$ gene mutation.

Previous genetic research have shown that SLCO2A 1 gene mutations is associated with decreased degradation of prostaglandin E, leading to skin hyperplasia, bone proliferation and mucosal defects in intestinal tract. Recently, a SLCO2A1 gene-related disease called primary hypertrophic osteoarthropathy (PHO) has been gaining interest, especially in China where an increasing number of case series on $\mathrm{PHO}$ have been reported. ${ }^{10-12}$ In a case series published in 2017, Li et al reported that among 36 patients with $\mathrm{PHO}$ who had SLCO2A1 gene mutations, approximately $60 \%$ of them had watery diarrhoea and $30 \%$ had anaemia. ${ }^{10}$ This suggests that lesions in digestive tract might have been present in these patients. However, none of these patients received a capsule endoscopy or BAE to inspect the morphological changes in small intestine. ${ }^{1011}$ In addition, despite the confirmed the presence of SLACO2A1 gene mutations and abdominal symptoms in Chinese patients with PHO, CEAS is currently considered a condition independent of $\mathrm{PHO}$ in China. ${ }^{11} 12$ There are also dermatological studies reporting SLCO2A1 gene mutations in patients who had pachydermoperiostosis. ${ }^{13} 14$ However, morphological changes in small intestinal have not been described in these patients. At the moment, no consensus has been reached between gastroenterologists, rheumatologist and dermatologists regarding the SLCO2A1 gene mutation-associated disorders. In our opinion, CEAS and PHO are likely to be different manifestations of the same pathological process. The two sides of one coin, in other words.

Finally, we call for more awareness of CEAS which we believe is a $S L C O 2 A 1$ gene mutation-related disease characterised by multiple small intestinal ulcers, along with hypertrophic osteoarthropathy and pachydermia. This entity mainly affects individuals of east-Asian ethnicity. International and multidisciplined collaborations are needed to improve our understanding of this complicated disease.

\footnotetext{
Author affiliations

${ }^{1}$ Center for Diagnostic and Therapeutic Endoscopy, School of Medicine, Keio University, Tokyo, Japan

${ }^{2}$ Department of Gastroenterology and Hepatology, Chinese PLA General Hospital, Beijing, China

${ }^{3}$ Division of Gastroenterology and Hepatology, Department of Internal Medicine, School of Medicine, Keio University, Tokyo, Japan
}

${ }^{4}$ Division of Dermatology, National Center for Child Health and Development, Tokyo, Japan

${ }^{5}$ Division of Orthopedics, National Center for Child Health and Development, Tokyo, Japan

Acknowledgements We sincerely thank Dr Abner JY Quek and Dr Wuen Lynn Tohor for their proofreading and critical comments and Professor Kenjiro Kosaki for the genetic analysis.

Contributors XS and NH wrote the paper. RM and KK performed capsule endoscopy. SM, KT and MN performed enteroscopy. HN examined skin lesion. AS examined X-ray films. HO and TK edited the paper.

Funding The authors have not declared a specific grant for this research from any funding agency in the public, commercial or not-for-profit sectors.

Competing interests None declared.

Patient consent Obtained.

Provenance and peer review Not commissioned; externally peer reviewed.

Open access This is an open access article distributed in accordance with the Creative Commons Attribution Non Commercial (CC BY-NC 4.0) license, which permits others to distribute, remix, adapt, build upon this work non-commercially, and license their derivative works on different terms, provided the original work is properly cited, appropriate credit is given, any changes made indicated, and the use is non-commercial. See: http://creativecommons.org/licenses/by-nc/4.0

\section{REFERENCES}

1. Pennazio M, Spada C, Eliakim R, et al. Small-bowel capsule endoscopy and device-assisted enteroscopy for diagnosis and treatment of small-bowel disorders: European Society of Gastrointestinal Endoscopy (ESGE) Clinical Guideline. Endoscopy 2015;47:352-86.

2. Matsumoto T, Nakamura S, Esaki M, et al. Endoscopic features of chronic nonspecific multiple ulcers of the small intestine: comparison with nonsteroidal anti-inflammatory drug-induced enteropathy. Dig Dis Sci 2006;51:1357-63.

3. Matsumoto T, Kubokura N, Matsui T, et al. Chronic nonspecific multiple ulcer of the small intestine segregates in offspring from consanguinity. J Crohns Colitis 2011;5:559-65.

4. Umeno J, Hisamatsu T, Esaki M, et al. A hereditary enteropathy caused by mutations in the SLCO2A1 Gene, Encoding a Prostaglandin Transporter. PLoS Genet 2015:11:e1005581.

5. Hosoe N, Ohmiya N, Hirai F, et al. Chronic enteropathy associated With SLCO2A1 Gene [CEAS]-characterisation of an enteric disorder to be considered in the differential diagnosis of Crohn's disease. J Crohns Colitis 2017;11:1277-81

6. Kohoutová D, Bures J, Tycová V, et al. Severe cryptogenic multifocal ulcerous stenosing enteritis. A report of three cases and review of the literature. Acta Medica 2010;53:25-9.

7. Chung SH, Park SU, Cheon JH, et al. Clinical characteristics and treatment outcomes of cryptogenic multifocal ulcerous stenosing enteritis in Korea. Dig Dis Sci 2015;60:2740-5.

8. Hwang J, Kim JS, Kim AY, et al. Cryptogenic multifocal ulcerous stenosing enteritis: radiologic features and clinical behavior. World $\mathrm{J}$ Gastroenterol 2017;23:4615-23.

9. Zhang Y, Huang L, Liu R, et al. Case report of a pair of siblings with cryptogenic multifocal ulcerating stenosing enteritis. Medicine 2017;96:e7527.

10. Li SS, He JW, Fu WZ, et al. Clinical, biochemical, and genetic features of 41 Han Chinese families with primary hypertrophic osteoarthropathy, and their therapeutic response to etoricoxib: results from a six-month prospective clinical intervention. J Bone Miner Res 2017;32:1659-66.

11. Zhang Z, He JW, Fu WZ, et al. Mutations in the SLCO2A1 gene and primary hypertrophic osteoarthropathy: a clinical and biochemical characterization. J Clin Endocrinol Metab 2013;98:E923-E933.

12. Zhang Z, Xia W, He J, et al. Exome sequencing identifies SLCO2A1 mutations as a cause of primary hypertrophic osteoarthropathy. Am J Hum Genet 2012;90:125-32.

13. Lee S, Park SY, Kwon $\mathrm{HJ}$, et al. Identification of the mutations in the prostaglandin transporter gene, SLCO2A1 and Clinical characterization in Korean patients with Pachydermoperiostosis. J Korean Med Sci 2016;31:735-42.

14. Niizeki H, Shiohama A, Sasaki T, et al. The complete type of pachydermoperiostosis: a novel nonsense mutation p.E141* of the SLCO2A1 gene. J Dermatol Sci 2014;75:193-5. 